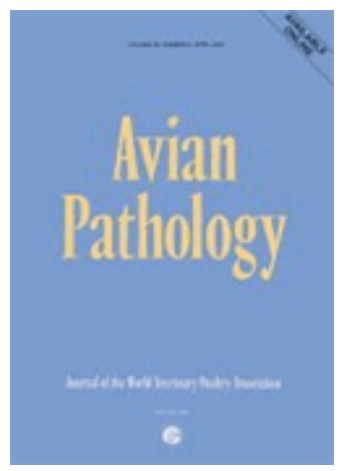

\title{
Morphometric evaluation of 'dysbacteriosis' in broilers
}

\begin{tabular}{|c|c|}
\hline Journal: & Avian Pathology \\
\hline Manuscript ID: & CAVP-2010-0124.R1 \\
\hline Manuscript Type: & Original Research Paper \\
\hline $\begin{array}{r}\text { Date Submitted by the } \\
\text { Author: }\end{array}$ & $15-$ Oct-2010 \\
\hline Complete List of Authors: & $\begin{array}{l}\text { Teirlynck, Emma; 1Institute for Agricultural and Fisheries Research } \\
\text { (ILVO), Animal Sciences Unit } \\
\text { De Gussem, Maarten; Vetworks } \\
\text { Dewulf, Jeroen; Ghent University, Department of Obstetrics, } \\
\text { reproduction and herd health } \\
\text { Haesebrouck, Freddy; Ghent University, Pathology, Bacteriology } \\
\text { and Avian Diseases } \\
\text { Ducatelle, Richard; Ghent University, Pathology, Bacteriology and } \\
\text { Avian Diseases } \\
\text { Van Immerseel, Filip; Ghent University, Pathology, Bacteriology and } \\
\text { Avian Diseases }\end{array}$ \\
\hline Keywords: & dysbacteriosis, broilers, morphometric evaluation, intestinal health \\
\hline
\end{tabular}

\section{SCHOLARONE"}

Manuscripts 


\section{Cavp-2010-0124.R1}

\section{Morphometric evaluation of 'dysbacteriosis' in broilers}

\section{E. Teirlynck ${ }^{1}$, M. DE Gussem ${ }^{2}$, J. Dewulf ${ }^{3}$, F. Haesebrouck ${ }^{4}$, R. Dycatelle ${ }^{4}$ and F. Van Immerseel $^{4^{*}}$}

${ }^{1}$ Institute for Agricultural and Fisheries Research (ILVO), Animal Sciences Unit, Scheldeweg 68, 9090 Melle, Belgium. ${ }^{2}$ Vetworks, Knokstraat 38, 9880 Poeke, Belgium.

${ }^{3}$ Department of Obstetrics, reproduction and herd health, Faculty of Veterinary Medicine, Ghent University, Salisburylaan 133, B-9820 Merelbeke, Belgium. ${ }^{4}$ Department of Pathology, Bacteriology and Avian Diseases, Research Group Veterinary Public Health and Zoonoses, Faculty of Veterinary Medicine, Ghent University, Salisburylaan 133, B-9820 Merelbeke, Belgium.

Short title: Dysbacteriosis in broilers

Received: 15 October 2010

Corresponding author.. Phone: (0032) 0926474 48. Fax: (0032) 0926474 94. E-mail: filip.vanimmerseel@UGent.be 


\begin{abstract}
In consequence of the withdrawal of products that assisted animal production, such as antimicrobial growth promoters, once controlled enteric diseases have returned and new multifactorial diseases causing gut disorders of unknown origin have emerged in broilers. One of these widespread syndromes causing intestinal health problems in broilers is in the field referred to as 'dysbacteriosis'. During this study the histopathology of the intestinal tract of broilers affected with dysbacteriosis was analyzed. Commercial broilers were given a macroscopic dysbacteriosis score by experienced veterinarians during necropsy. Samples from duodenum and cecum were taken from each broiler for histopathological analysis. An increase in the macroscopical dysbacteriosis score coincided with increased villus atrophy, a decrease in the thickness of the tunica muscularis and an increase in T-lymphocyte infiltration in the gut mucosa. Also more and larger goblet cells were observed in the animals with high macroscopical dysbacteriosis scores. Although the exact etiology still remains to be identified, dysbacteriosis in broiler chickens thus coincides with an inflammatory reaction in the gut mucosa.
\end{abstract}

Keywords: 


\section{Introduction}

Since the ban of antimicrobial growth promoters (AGPs) in Europe, the broiler industry is facing a rise in intestinal health problems, collectively referred to as 'dysbacteriosis' among practitioners (Eshuis et al., 1998; Fabri, 2000; Rebel et al., 2006; De Gussem, 2007). Dysbacteriosis has been defined as the presence of a qualitatively and/or quantitatively abnormal microbiota in the proximal parts of the small intestine, inducing a cascade of reactions in the gastro-intestinal tract including reduced nutrient digestibility and impaired intestinal barrier function, increasing the risk of bacterial translocation and inflammatory responses (Fabri, 2000; Panneman, 2000; van der Klis \& Lensing, 2007).

The syndrome is generally seen between 20 and 30 days of age (Fabri, 2000; Pattison, 2002; Wilson et al., 2005). Clinically, the main symptoms are: pale, glistening or orange droppings with undigested feed particles, wet and greasy droppings and hence dirty feathers, sometimes foamy cecal droppings, reduced physical activity, increased water intake, a decrease in feed intake with a check in weight or reduced gain rates and an increased feed conversion (Fabri, 2000; Pattison, 2002; Wilson et al., 2005; De Gussem, 2007). At necropsy the main observations are thin, fragile, often translucent intestinal walls, watery or foamy intestinal contents and frequent orange mucus and undigested particles in the intestines, ballooning of the gut and intestinal inflammation (Pattison, 2002; De Gussem, 2007).

It is believed that both non-infectious and infectious factors can play a role in dysbacteriosis (Mortimer, 2002; De Gussem, 2007). Suspected non-infectious factors are different types of non-specific stressors, such as feed interruptions or dietary changes, nutritional imbalance, dietary stressors such as soluble 'non-starch polysaccharides' (NSP), 
management disorders, genetic background, enzymatic dysfunction, and mycotoxins (Langhout et al., 1999; De Gussem, 2007; Teirlynck et al., 2009). Infectious agents that potentially play a role in dysbacteriosis are coccidia, Clostridium perfringens and other unidentified bacteria producing toxic metabolites (Morrow, 2001; De Gussem, 2007). Despite the widespread nature and importance of the syndrome, there is a lack of scientific literature and still a lot of controversy about the exact etiology and up until today the basis of the underlying pathophysiology is unknown. Hence, diagnosis faces a lot of challenges in broilers due to the incomplete characterization of the syndrome (Wilson et al., 2005).

The purpose of the present study was to gain insight in the histopathological changes at the level of the intestinal mucosa in field cases of dysbacteriosis.

\section{Materials and methods}

Animals and sampling. Twelve 18 days old ( 2 flocks, 1 broiler farm), thirty-eight 21 days old (4 flocks, 2 broiler farms), thirty-six 28 days old ( 2 flocks, 1 broiler farm) and eighteen 42 days old (1 flock, 1 broiler farm) male Ross 308 broiler chickens were used in the study. In total broilers of nine flocks from four different broiler farms were sampled. The flocks have been selected ad random from an integrated poultry enterprise, thus all the birds originated from the same breeder flocks and were given similar feed including anticoccidials. The birds were receiving nicarbazin/narasin in starter phase (day 1 until day 18) and salinomycin in grower phase until 30 days of age at registered doses. This enterprise was reported by the field veterinarian to have above average intestinal health problems, including 
dysbacteriosis, coccidiosis (mainly Eimeria maxima) and wet litter, although the (ventilation) management was evaluated as better than average. The birds that were selected were not clinically ill, and were considered as average, healthy birds by an experienced poultry veterinarian.

The chickens were euthanized by means of cervical dislocation by an experienced veterinarian and immediately necropsied. Intestinal parameters were scored (see below). Samples of approximately $3 \mathrm{~cm}$ were taken from the second limb of the duodenum and the middle part of one caecum, rinsed in PBS and fixed in $4 \%(\mathrm{v}: \mathrm{v})$ buffered formalin.

Macroscopical scoring system. (Figure 1) Each bird was given a score between 0 and 10 for intestinal dysbacteriosis parameters, 0 being a normal gastrointestinal tract and 10 being the most severe dysbacteriosis. In total 10 parameters were assessed and scored 0 when absent and 1 when present. The parameters are: (1) ballooning of the gut; (2) significant redness of the serosal and/or mucosal side of the gut and/or presence of abnormally dilated blood vessels on the serosal side of the gut, cranial from Meckel's diverticulum; (3) a macroscopic visible and/or tangible reduction of the gut wall thickness and/or translucent guts in combination with increased fragility of the gut cranial from Meckel's diverticulum; (4) when 3 seconds after dissecting the gut, the edges of the gut cranial from Meckel's diverticulum are flaccid; (5) an abnormal appearance of the contents in the lumen of the gut (excessive slime, water, gas, greasy aspect or mixture of these) cranial from Meckel's diverticulum; (6) significant redness of the serosal and/or mucosal side of the gut and/or presence of abnormally dilated blood vessels on the serosal side of the gut, caudal from Meckel's diverticulum; (7) a macroscopic visible and/or tangible reduction of the gut wall 
thickness and/or translucent guts in combination with increased fragility of the gut caudal from Meckel's diverticulum; (8) when 3 seconds after dissecting the gut, the edges of the gut caudal from Meckel's diverticulum are flaccid; (9) abnormal appearance of the contents in the lumen of the gut (excessive slime, water, gas, greasy aspect or mixture of these) caudal from Meckel's diverticulum; (10) undigested feed particles caudal from ileo-caecal junction (De Gussem, 2010). During this lesion scoring, no intestinal sections were given score 0, 9 or 10 .

Morphological examination. Formalin fixed intestinal segments were dehydrated in xylene, and embedded in paraffin. Sections of $4 \mu \mathrm{m}$ were cut using a microtome (Microm, Prosan, Merelbeke, Belgium). Deparaffinization was done in xylene ( 2 x 5 min). Then the sections were rehydrated in isopropylene (5 $\mathrm{min}), 95 \%$ alcohol (5 min) and 50\% alcohol (5 min) and stained with haematoxylin and eosin. Histological lesions were studied using standard light microscopy. Villus length in duodenum was measured by random measurement of 9 villi per section using an Olympus BX61 Digital Camera DP50 (Olympus NV, Aartselaar, Belgium) and a computer based image analysis system, Analysis ${ }^{\circledR} \mathrm{J}-2$ (P4 technologies, inc., Waldorf, Maryland, US). Only intact villi were measured, meaning villi for which the tip as well as the base of the villus were in the plane of the section. Thickness of the tunica muscularis in duodenum and ceca was also measured using the Analysis ${ }^{\circledR} \mathrm{J}-2$ software. For each section 8 measurements were performed on different locations. Measurements were done on cross sections of ring shaped intestinal segments which allow unbiased perpendicular measurements. Detection of goblet cells was done using Periodic Acid Schiff staining as described by Forder et al. (2007) 
Immunohistochemical examination. Deparaffinization of paraffin-embedded tissue sections $(4 \mu \mathrm{m})$ was performed as described above. The pressure cooker antigen retrieval method (Tender Cooker, Nordic Ware, Minneapolis, USA) was applied to the samples. Immunohistochemical labelling of leukocytes was performed as described by Mast et al. (1998). Briefly, endogenous peroxidase in the tissue sections was blocked with $\mathrm{H}_{2} \mathrm{O}_{2}(3 \%)$ in methanol for $30 \mathrm{~min}\left(21^{\circ} \mathrm{C}\right)$. After rinsing with PBS sections were incubated for $1 \mathrm{~h}\left(21^{\circ} \mathrm{C}\right)$ with monoclonal antibodies directed against T-lymphocytes (KUL05). After rinsing thoroughly, a goat anti-mouse IgG1 conjugate, labeled with peroxidase (Dako, Heverlee, Belgium) was added for $30 \mathrm{~min}\left(21^{\circ} \mathrm{C}\right)$. After rinsing again, tissue sections were incubated with ABC HRP complex (Dako, Heverlee, Belgium) for $30 \mathrm{~min}\left(21^{\circ} \mathrm{C}\right)$. After another rinse, positive cells were stained brown after conversion of the substrate (3,3' diaminobenzidine tetrahydrochloride, Sigma, St. Louis, USA) in the presence of $\mathrm{H}_{2} \mathrm{O}_{2}$. The number of Tlymphocytes in the propria mucosae was scored with an automatic image analysis system (Optimas 6.5., Media Cybernetics, Silver Spring, USA), measuring the area percentage occupied by the labeled cells. For each section, eight randomly selected sites were analyzed by the image analysis program.

Statistical analysis. The relation between the macroscopic lesion score and the outcome variables villus length, thickness of the tunica muscularis and T-lymphocyte infiltration was evaluated by means of a linear mixed model taking into account the chicken as a random factor since multiple observations were made on one animal. In addition other co-variables such as age of the bird, person scoring the bird and intestinal segment were also taken into 
account. First, all independent variables were tested univariably and subsequently all significant variables were included in a multivariable model. In this multivariable model also all 2-way interactions were tested. In the multivariable model all main effects and interactions with a p-value $<0.05$ were retained. For the outcome variables that were not normally distributed, a log transformation was performed. Model fit was evaluated by means of evaluation of the residuals. The number of chickens belonging to a certain macroscopical dysbacteriosis score group per age group is shown in Table 1.

\section{Results}

Intestinal morphology. Villus length. Duodenal villus length generally decreased with an increase in the macroscopic 'dysbacteriosis' score within one age group (Table 2). Statistical analysis showed that, starting from macroscopical dysbacteriosis score 5, villus length was significantly lower compared to macroscopical dysbacteriosis score $1(\mathrm{p}=0.01)$. Score 8 differed significantly from score 5, 6 and $7(\mathrm{p}=0.03)$.

Cystic crypts. In the duodenum a mild to severe dilatation of the crypts of Lieberkühn was observed. Although not quantitatively analyzed the number of cystic crypts appeared to increase with age and with the macroscopic dysbacteriosis score. The age effect seemed to have the highest impact.

Thickness of the tunica muscularis. For each age interval, the thickness of the tunica muscularis generally decreased with an increasing macroscopical dysbacteriosis score (Table 
3). Statistical analysis showed that the thickness of the tunica muscularis of the gut of the animals having macroscopical dysbacteriosis score 5 and higher was significantly lower as compared to score $1(\mathrm{p}=0.01)$.

Goblet cells. Although not quantitatively analyzed, periodic acid schiff staining generally showed more and larger goblet cells both on the villi and in the crypts of the gut of animals with higher macroscopical dysbacteriosis scores.

T-lymphocyte infiltration. Generally T-lymphocyte infiltration in duodenum and caecum increased within one age-group, with increased macroscopical dysbacteriosis scores (Table 4). Statistical analysis showed that T-lymphocyte infiltration in the gut mucosa of animals having a macroscopical dysbacteriosis score of 6 and higher was significantly higher as compared to score $1(\mathrm{p}=0.02)$.

\section{Discussion}

Definitive diagnosis of dysbacteriosis has been challenging due to the non-specific nature of the clinical signs and lesions and because the etiology is still unknown (Wilson et al., 2005). The present study has identified several more or less characteristic changes, which may aid in confirming the diagnosis of 'dysbacteriosis', and which help differentiating this entity from other intestinal disorders, such as malabsorption syndrome (MAS) and runting-stunting syndrome (RSS).

MAS has been described as a gastro-intestinal disease affecting broilers during the 
first two weeks post-hatch (Zekarias et al., 2002; van Hemert et al., 2004). The main clinical symptoms of MAS are weight gain depression with non-uniform growth, stunting, diarrhea with undigested food particles resulting in wet litter, retarded and defective feathering, pigment loss, distended abdomens, depression and early mortality. At necropsy, lesions are found in the digestive organs, especially the small intestine, which is grossly pale and distended, with mucoid contents, and there is lower mineralization of the thigh bones (Kouwenhoven et al., 1978a, b; Bracewell \& Randall, 1984; Reece et al., 1984; Szabo et al., 1989; Reece \& Frazier, 1990; McNulty \& McFerran, 1993; Sályi \& Glávitis, 1999;

Songserm et al., 2002a, b; Van Hemert et al., 2004; Rebel et al., 2006). Histologically, intestinal lesions such as cystic crypts of Lieberkühn and villus atrophy are observed (Rebel et al., 2004).

RSS is typically affecting birds within the first two weeks of life and can be defined as a syndrome in which a number of individuals in a flock appear considerably small due to delayed growth (Dufour-Zavala, 2005; Nili et al., 2007). Clinically, the main symptoms of RSS are immobility, increased feed conversion and poor performance, uneven growth and stunting, little eating and excessive water consumption, diarrhea, retarded and defective feathering, distended abdomens and bone defects (Vertommen et al., 1980a, b; Ruff, 1982; Calnek et al., 1997; Shapiro et al., 1997; 1998; Sályi and Glávits, 1999; Dufour-Zavala, 2005; Nili et al., 2007). At necropsy lesions are found in the small intestine, which is pale and thin, almost translucent, containing undigested food particles.

A main difference between dysbacteriosis and MAS/RSS, of which the latter could be identical entities with different names, is that in field cases of dysbacteriosis, the growth retardation due to poorer absorption of nutrients is probable but very often average growth 
will still be in line with breed standards, and also the homogeneity of the flock will typically not be dramatically affected as with RSS/MAS. Also the age of disease induction is lower (below 2 weeks of age) in MAS/RSS as compared to dysbacteriosis (3-4 weeks of age). Dysbacteriosis and MAS/RSS are clearly distinct from subclinical necrotic enteritis because no ulcerations in the gut are found.

In the dysbacteriosis field cases, duodenal villus length, and thickness of the tunica muscularis and T-lymphocyte infiltration in the mucosa of duodenum and caecum were altered. No necrotic lesions were observed. This combination of morphological and inflammatory changes combined with the different clinical appearance compared to other syndromes (such as MAS/RSS) is in our opinion sufficiently unique and characteristic to classify this syndrome as a separate entity, although microscopical measurements of MAS/RSS samples are necessary for confirmation. The microscopical findings of dysbacteriosis may explain the clinical signs, being depressed growth, wet litter and clinical depression (Toskes et al., 1975; Kaldhusdal \& Hofshagen, 1992; Hoerr, 2001). Based on the measurements, variations in intestinal distention between healthy gut and severe dysbacteriosis can explain the variations in thickness of the tunica muscularis. Thus ballooning of the gut and the flaccid aspect of the gut wall may be directly associated with reduced tonus / rigor of the tunica muscularis. Variations in intestinal distention however can only partly explain the reduction in villus length and increase in villus thickness as observed in the severe dysbacteriosis cases. Thus severe dysbacteriosis is associated with an absolute reduction in available absorptive surface area. The change in the size and number of goblet cells could explain the mucous content of the intestinal tract of affected birds. Cystic crypt 
formation could be due to a vitamin deficiency as a secondary effect of the malabsorption caused by villus atrophy and increased T-lymphocyte infiltration (Klasing \& Austic, 2003).

Dysbacteriosis is defined in human medicine as a condition characterized by a shift in the microbiota favoring abnormal populations of bacteria to predominate within the intestinal tract with minimal intestinal pathology (Schoorel et al., 1980; Dumitrasco et al., 1980; Sidorchuk \& Bondarenko, 1984; Klemparskaya et al., 1987). Despite the definition of dysbacteriosis, the microbiota composition and possible microbiota shifts have not been studied and the name dysbacteriosis is not really substantiated. However there are indications suggesting that the intestinal microbiota composition may play a role in this syndrome. These indications include the response to certain antibiotic treatments, the consistency of the droppings and the inflammatory nature of the intestinal lesions.

In conclusion, dysbacteriosis in broilers is characterized by villus atrophy, a decrease in the thickness of the tunica muscularis and an increase in T-lymphocyte infiltration in the gut mucosa. These histological observations can explain performance problems and macroscopical observations of the gut at necropsy, in broilers with dysbacteriosis.

\section{Acknowledgments}

We would like to thank Sarah Loomans, Christian Puttevils and Delphine Ameye for their skilful technical assistance. Dieter Vancraeynest and Maja Mariën (Alpharma) are acknowledged for their help with macroscopical lesion scoring. This work was funded by grant S6169 of the Federal Public Service Health, Food Chain Safety and Environment. 


\section{References}

Bracewell, C.D. \& Randall, C.J. (1984). The infectious stunting syndrome. World's Poultry Science Journal, 40, 31-37.

Calnek, B.G., Barenes, H.J., Bread, C.W., McDouglad, L.R. \& Saif, Y.M. (Eds.) (1997).

Diseases of Poultry 10th edn. Ames: Iowa State Press.

De Gussem, M. (2007). Coccidiosis in poultry: review on diagnosis, control, prevention and interaction with overall gut health. Proceedings of the XVI European Symposium on Poultry Nutrition (pp. 160-169). Strasbourg, France.

De Gussem, M. (2010). Macroscopic scoring system for bacterial enteritis in broiler chickens and turkeys. WVPA meeting. Merelbeke, Belgium.

Dufour-Zavala, L. (2005). Cystic enteritis: reproduction of the disease and attempted control measures. Proceedings of the 40th National Meeting on Poultry Health and Processing (pp. 20-21). Ocean City, Maryland.

Dumitrasco, D., Grigoresco, M., Parau, N., Suciu, A. \& Erdosy, S. (1980). Dysbacteriosis in enteropathies. Medicine Interne, 18, 239-245.

Eshuis, J.W., Van Dobbenburgh, O.A., Delhaes, L.M., Van Der Meij, D. \& Nijland, J. T. (1998). Bacterie-regelaar Tylan helpt tegen dysbacteriose. Pluimveehouderij, 13.

Fabri T.H.F. (2000). Necrotic enteritis, Clostridial enteritis or dysbacteriosis? Proceedings of the Elanco Symposium. Cork, Ireland.

Forder, R.E., Howarthe, G.S., Tivey, D.R. \& Hughes, R.J. (2007). Bacterial modulation of small intestinal goblet cells and mucin composition during early posthatch development of poultry. Poultry Science, 86, 2396-2403.

Hoerr, F.J. (2001). Intestinal integrity and the impact of losing it. World Poultry-Elsevier, 17, 
16-18.

Kaldhusdal, M. \& Hofshagen, M. (1992). Barley inclusion and Avoparcin supplementation in broiler diets. 2. Clinical, pathological, and bacteriological findings in a mild form of necrotic enteritis. Poultry Science, 71, 1145-1153.

Klasing, K. \& Austic, R.E. (2003). Nutritional Diseases. In Y.M. Saif, \& D.E. Swayne (Eds.). Diseases of Poultry 11th edn (pp.1027-1053). Ames: Iowa State Press.

Klemparskaya, N.N., Pinegin, B.V., Shal'nova, G.A., Korshunov, V.M., Maltsev, V.N., Glad'ko, I.A., Kuz'mina, T.D., Ulanova, A.M., Dobronravova, N.N. \& Yermolov, V.V. (1987). Normalizing effect of immunoglobulins in the treatment of endogenous infection and intestinal dysbacteriosis in irradiated mice. Journal of Hygiene, Epidemiology, Microbiology and Immunology, 31, 91- 98.

Kouwenhoven, B., Vertommen, M. \& Vaneck, J.H.H. (1978a). Runting and leg weakness in broilers - involvement of infectious factors. Veterinary Science Communications, 2, 253-259. Kouwenhoven, B., Davelaar, F.G. \& Vanwalsum, J. (1978b). Infectious proventriculitis causing runting in broilers. Avian Pathology, 7, 183-187.

Langhout, D.J., Schutte, J.B., Van Leeuwen, P., Wiebenga, J. \& Tamminga, S. (1999). Effect of dietary high- and low- methylated citrus pectin on the activity of the ileal microflora and morphology of the small intestinal wall of broiler chicks. British poultry science, 40, 340347.

Mast, J., Goddeeris, B.M., Peeters, K., Vandesande, F. \& Berghman, L.R. (1998).

Characterisation of chicken monocytes, macrophages and interdigitating cells by the monoclonal antibody KUL01. Veterinary Immunology and Immunopathology, 61, 343-357. 
McNulty, M.S. \& McFerran, J.B. (1993). The runting stunting syndrome general assessment. In J.B. McFerran \& M.S. McNulty (Eds.). Virus infections of birds (pp. 519-528). Elsevier, Amsterdam.

Morrow, C. (2001). Solving the problems of necrotic enteritis. British Poultry Science, 42, 64-68.

Mortimer, I. (2002). The Detection of Dysbacteriosis. Proceedings of the Elanco Global Enteritis Symposium. Cambridge, UK.

Nili, H., Jahantigh, M. \& Nazifi, S. (2007). Clinical observation, pathology, and serum biochemical changes in infectious stunting syndrome of broiler chickens. Comparative Clinical Pathology, 16, 161-167.

Panneman, H. (2000). Clostridial enteritis/dysbacteriosis, fast diagnosis by T-RFLP, a novel diagnostic tool, Proceedings of the Elanco Global Enteritis Symposium. Cork, Ireland. Pattison, M. (2002). Some clinical and pathological features of enteritis in broilers observations on treatment in the UK. Proceedings of the Elanco Global Enteritis Symposium (pp.1-7). Cambridge, UK.

Rebel, J.M.J., van Dam, J.T.P., Zekarias, B., Balk, F.R.M., Post, J., Minambres, A.F. \& ter Huurne, A.A.H.M. (2004). Vitamin and trace mineral content in feed of breeders and their progeny: effects of growth, feed conversion and severity of malabsorption syndrome of broilers. British Poultry Science, 45, 201-209.

Rebel, J.M.J., Balk, F.R.M., Post, J., Van Hemert, S., Zekarias, B. \& Stockhofe, N. (2006). Malabsorption syndrome in broilers. World's Poultry Science Journal, 62, 17-29. 
Reece, R.L., Hooper, P.T., Tate, S.H., Beddome, V.D., Forsyth, W.M., Scott, P.C. \& Barr, D.A. (1984). Field, clinical and pathological observations of a runting and stunting syndrome in broilers. Veterinary Record, 115, 483-485.

Reece, R.L. \& Frazier, J.A. (1990). Infectious stunting syndrome of chickens in GreatBritain - field and experimental studies. Avian Pathology, 19, 723-758.

Ruff, M.D. (1982). Nutrient Absorption and Changes in Blood-Plasma of Stunted Broilers. Avian Diseases, 26, 252-259.

Sályi, G. \& Glávits, R. (1999). Infectious stunting syndrome associated with disturbances of mineral metabolism and bone development in broiler chickens. Acta Veterinaria Hungarica, $47,361-378$.

Schoorel, E.P., Giesberts, M.A., Blom, W. \& Van Gelderen, H.H. (1980). D-Lactic acidosis in a boy with short bowel syndrome. Archives of Disease in Childhood, 55, 810-812.

Shapiro, F., Mahagna, M. \& Nir, I. (1997). Stunting syndrome in broilers: Effect of glucose or maltose supplementation on digestive organs, intestinal disaccharidases, and some blood metabolites. Poultry Science, 76, 369-380.

Shapiro, F., Nir, I. \& Heller, D. (1998). Stunting syndrome in broilers: Effect of stunting syndrome inoculum obtained from stunting syndrome affected broilers, on broilers, leghorns and turkey poults. Poultry Science, 77, 230-236.

Sidorchuk, I.I. \& Bondarenko, V.M. (1984). Selection of a biologically active mutant of Propionibacterium shermanii and the possibility of its use in complex therapy of enteral dysbacteriosis. Journal of Hygiene, Epidemiology, Microbiology and Immunology, 28, 331338. 
Songserm, T., Engel, B., van Roozelaar, D.J., Kok, G.L., Pijpers, A., Pol, J.M.A. \& ter Huurne, A.A.H.M. (2002a). Cellular immune response in the small intestine of two broiler chicken lines orally inoculated with malabsorption syndrome homogenates. Veterinary Immunology and Immunopathology, 85, 51-62.

Songserm, T., Zekarias, B., van Roozelaar, D.J., Kok, R.S., Pol, J.M.A., Pijpers, A. \& ter Huurne, A.A.H.M. (2002b). Experimental reproduction of malabsorption syndrome with different combinations of reovirus, Escherichia coli, and treated homogenates obtained from broilers. Avian Diseases, 46, 87-94.

Szabo, J., Salyi, G. \& Rudas, P. (1989). Effect of malabsorption-syndrome on pancreatic function in broilers. Poultry Science, 68, 1553-1560.

Teirlynck, E., Bjerrum, L., Eeckhaut, V., Huygebaert, G., Pasmans, F., Haesebrouck, F., Dewulf, J., Ducatelle, R. \& Van Immerseel F. (2009). The cereal type in feed influences gut wall morphology and intestinal immune cell infiltration in broiler chickens. British Journal of Nutrition, 102, 1453-1461.

Toskes, P.P., Giannella, R.A., Jervis, H.R., Rout, W.R. \& Takeuchi, A. (1975). Small intestinal mucosal injury in the experimental blind loop syndrome; light and electronmicroscopic and histochemical studies. Gastroenterology, 68, 1193-1203.

van der Klis, J.D. \& Lensing, M. (2007). Wet litter problems relate to host-microbiota interactions. World Poultry, 23, 20-22.

Van Hemert, S., Hoekman, A.J., Smits, M.A. \& Rebel, J.M.J. (2004). Differences in intestinal gene expression profiles in broiler lines varying in susceptibility to malabsorption syndrome. Poultry Science, 83, 1675-1682. 
Vertommen, M., Vaneck, J.H.H., Kouwenhoven, B. \& Vankol, N. (1980a). Infectious stunting and leg weakness in broilers. Pathology and biochemical-changes in blood-plasma. Avian Pathology, 9, 133-142.

Vertommen, M., Vanderlaan, A. \& Veenendaalhesselman, H.M. (1980b). Infectious stunting and leg weakness in broilers. Studies on alkaline-phosphatase iso-enzymes in blood-plasma. Avian Pathology, 9, 143-152.

Wilson, J., Tice, G., Brash, M.L. \& St Hilaire, S. (2005). Manifestations of Clostridium perfringens and related bacterial enteritides in broiler chickens. Worlds Poultry Science Journal, 61, 435-449. Zekarias, B., Songserm, T., Post, J., Kok, G.L., Pol, J.M.A., Engel, B. \& ter Huurne, A.A.H.M. (2002). Development of organs and intestinal mucosa leukocytes in four broiler lines that differ in susceptibility to malabsorption syndrome. Poultry Science, 81, 1283-1288. 
Table 1. Number of chickens analyzed per age per macroscopic dysbacteriosis group. Of each chicken both duodenum and caecum were analyzed.

- : No birds of this age group were given this score.

\begin{tabular}{|c|c|c|c|c|c|c|c|c|}
\hline \multirow[t]{2}{*}{ Age } & \multicolumn{8}{|c|}{ Macroscopic 'Dysbacteriosis' Score } \\
\hline & 1 & 2 & 3 & 4 & 5 & 6 & 7 & 8 \\
\hline 18 days & - & 1 & 4 & 4 & 3 & - & - & - \\
\hline 21 days & & 3 & 4 & 13 & 4 & 8 & 5 & 1 \\
\hline 28 days & 1 & 3 & - & 3 & 13 & 6 & 6 & 4 \\
\hline 42 days & 1 & 1 & 1 & 2 & 4 & 6 & 1 & 2 \\
\hline
\end{tabular}


Table 2. Length of villi $(\mu \mathrm{m})$ in duodenal sections in relation to the macroscopic score.

Random measurements of 9 villi per 3 gut sections were performed by a computer based analysis system. The given values \pm standard deviations are the means of 9 villi measured in the chickens from the same age and in the same macroscopic 'dysbacteriosis' score category.

- : No birds of this age group were given this score.

\begin{tabular}{|c|c|c|c|c|c|c|c|c|}
\hline \multirow[t]{2}{*}{ Age } & \multicolumn{8}{|c|}{ Macroscopic 'Dysbacteriosis' Score } \\
\hline & 1 & 2 & 3 & 4 & 5 & 6 & 7 & 8 \\
\hline 18 days & - & $\begin{array}{l}1988 \\
\pm 153\end{array}$ & $\begin{array}{l}1668 \\
\pm 219\end{array}$ & $\begin{array}{l}1627 \\
\pm 188\end{array}$ & $\begin{array}{l}1550 \\
\pm 201\end{array}$ & - & - & - \\
\hline 21 days & - & $\begin{array}{l}2125 \\
\pm 260\end{array}$ & $\begin{array}{l}1929 \\
\pm 239\end{array}$ & $\begin{array}{l}2006 \\
\pm 292\end{array}$ & $\begin{array}{l}1870 \\
\pm 219\end{array}$ & $\begin{array}{l}1694 \\
\pm 54\end{array}$ & $\begin{array}{l}1491 \\
\pm 193\end{array}$ & $\begin{array}{l}1495 \\
\pm 126\end{array}$ \\
\hline 28 days & $\begin{array}{l}2656 \\
\pm 245\end{array}$ & $\begin{array}{l}1866 \\
\pm 152\end{array}$ & - & $\begin{array}{l}2173 \\
\pm 269\end{array}$ & $\begin{array}{l}1878 \\
\pm 290\end{array}$ & $\begin{array}{l}1812 \\
\pm 415\end{array}$ & $\begin{array}{l}1762 \\
\pm 336\end{array}$ & $\begin{array}{l}1479 \\
\pm 212\end{array}$ \\
\hline 42 days & $\begin{array}{l}2439 \\
\pm 151 \\
\end{array}$ & $\begin{array}{l}2471 \\
\pm 81\end{array}$ & $\begin{array}{l}2847 \\
\pm 222 \\
\end{array}$ & $\begin{array}{l}2364 \\
\pm 185\end{array}$ & $\begin{array}{l}2049 \\
\pm 208\end{array}$ & $\begin{array}{l}2078 \\
\pm 289 \\
\end{array}$ & $\begin{array}{l}2527 \\
\pm 190\end{array}$ & $\begin{array}{l}1862 \\
\pm 180\end{array}$ \\
\hline
\end{tabular}


Table 3. Thickness of the tunica muscularis $(\mu \mathrm{m})$ in duodenal and caecal sections in relation to the macroscopic score. 8 random measurements of the thickness of the tunica muscularis per 3 gut sections were performed by a computer based analysis system. The given values \pm standard deviations are the means of 8 random measurements of both duodenum and caecum of the chickens in the same age and in the same macroscopic 'dysbacteriosis' score category.

- : No birds of this age group were given this score.

\begin{tabular}{lllllllll}
\hline Age & \multicolumn{9}{l}{ Macroscopic 'Dysbacteriosis' Score } & & & & \\
& 1 & 2 & 3 & 4 & 5 & 6 & 7 & 8 \\
\hline \multirow{2}{*}{18 days } & - & 197 & 152 & 143 & 119 & - & - & - \\
& & \pm 22 & \pm 28 & \pm 25 & \pm 16 & & & \\
& & & & & & & & \\
21 days & - & 233 & 186 & 178 & 174 & 144 & 144 & 127 \\
& & \pm 40 & \pm 30 & \pm 39 & \pm 33 & \pm 16 & \pm 27 & \pm 23 \\
28 days & 293 & 306 & - & 253 & 211 & 185 & 170 & 151 \\
& \pm 76 & \pm 105 & & \pm 62 & \pm 52 & \pm 37 & \pm 26 & \pm 23 \\
& & & & & & & & \\
42 days & 327 & 329 & 277 & 246 & 205 & 193 & 195 & 165 \\
& \pm 61 & \pm 91 & \pm 45 & \pm 77 & \pm 29 & \pm 45 & \pm 21 & \pm 30 \\
\hline
\end{tabular}


Table 4. T-lymphocyte infiltration (area percentage) for duodenal and caecal sections in relation to the macroscopic score. 8 random measurements of the T-lymphocyte infiltration in the mucosa per 3 gut sections were performed by a computer based analysis system. The given values \pm standard deviations are the means of the 8 random measurements of both duodenum and caecum of the chickens in the same age and in the same macroscopic 'dysbacteriosis' score category.

- : No birds of this age group were given this score

\begin{tabular}{lllllllll}
\hline Age & \multicolumn{9}{l}{ Macroscopic 'Dysbacteriosis' Score } \\
& 1 & 2 & 3 & 4 & 5 & 6 & 7 & 8 \\
\hline \multirow{2}{*}{18 days } & - & 4.72 & 5.64 & 5.54 & 6.52 & - & - & - \\
& & \pm 1.70 & \pm 2.36 & \pm 2.14 & \pm 3.31 & & & \\
& & & & & & & & \\
21 days & - & 4.06 & 5.05 & 5.56 & 5.10 & 6.30 & 6.80 & 8.20 \\
& & \pm 1.70 & \pm 2.01 & \pm 2.64 & \pm 2.35 & \pm 3.10 & \pm 3.05 & \pm 1.95 \\
& & & & & & & & \\
28 days & 5.59 & 7.93 & - & 7.70 & 7.48 & 10.24 & 8.74 & 11.00 \\
& \pm 1.80 & \pm 3.88 & & \pm 3.19 & \pm 2.83 & \pm 3.19 & \pm 3.66 & \pm 3.06 \\
& & & & & & & & \\
42 days & 7.82 & 6.97 & 8.44 & 5.57 & 7.24 & 8.61 & 7.69 & 9.50 \\
& \pm 2.35 & \pm 1.47 & \pm 2.20 & \pm 1.72 & \pm 2.58 & \pm 2.71 & \pm 1.33 & \pm 2.01 \\
\hline
\end{tabular}


Figure 1. Macroscopic dysbacteriosis score system parameters. A. Overall gut ballooning; B. Content of the intestinal tract, 1. Mucoid, orange intestinal content, 2. Foamy intestinal content; $\boldsymbol{C}$. Tonus of the intestinal tract, 1. Good tonus, 2. Lack of tonus; D. Macroscopically visible thickness of the intestinal tract, 1. Macroscopically thin intestinal tract, 2. Intestinal tract with normal thickness; $\boldsymbol{E}$. Undigested particles in the colon (arrows); $\boldsymbol{F}$. Inflammation of the gut, 1. Inflammation, 2. No inflammation. 


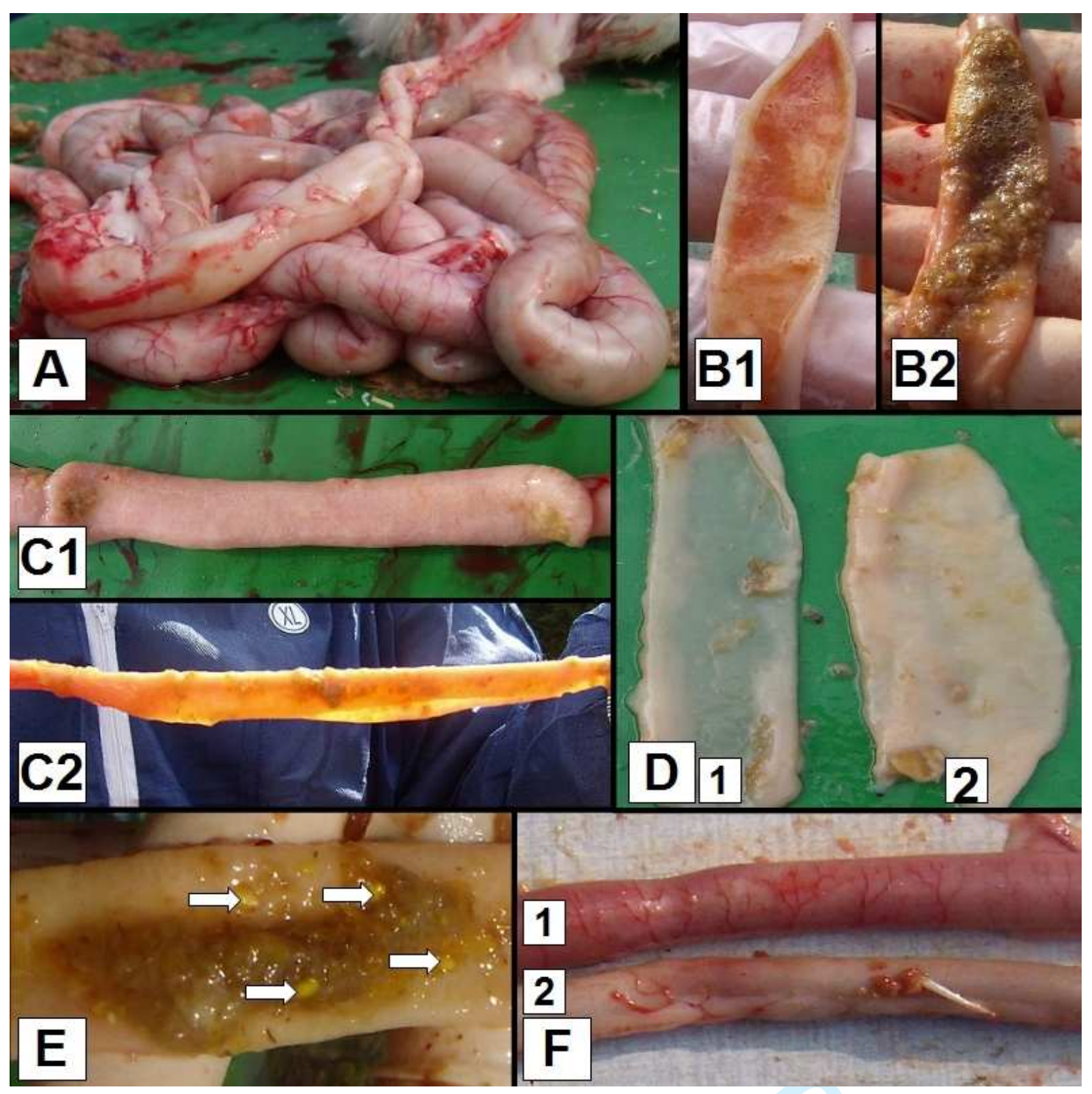

